\title{
Experimental and computational comparative study of the specimens loaded by bending and torsion
}

\author{
Lenka Jakubovičová ${ }^{1, *}$, Milan Vaško ${ }^{1}$, Milan Sága ${ }^{1}$, Peter Kopas ${ }^{1}$ \\ ${ }^{1}$ University of Žilina, Faculty of Mechanical Engineering, Department of Applied Mechanics, \\ Univerzitná 8215/1, Žilina, Slovakia
}

\begin{abstract}
The article presents the theoretical and computational analysis of the fatigue tested specimens loaded by bending and torsion. The testing device allows loading by constant turn of the clamping parts. The stress and strain magnitude in test depends on the material characteristics and shape of the specimen. The calculations are realized by finite element method (FEM). The obtained results are verified with the experimental measurement applying the optical system ARAMIS.
\end{abstract}

Keywords: bending, torsion, calibration curve, Finite Element Method (FEM), optical system ARAMIS, ADINA

\section{Introduction}

The multiaxial fatigue equipment has been designed for the purpose of experimental measurement fatigue curves of test specimen. For evaluation of fatigue curves it is necessary to know stress and strain conditions on individual loading levels. The stress and strain magnitude in test sample is dependent on shape and material of the specimen. Exact solution of stress and strain values is difficult and FE method [1] and experimental measurement (optical system ARAMIS) were used for their specification [2].

\subsection{Test equipment design}

Design of experimental equipment has been based on mechanical principle. The fixed rotation is generated by excenter and linkage mechanism. A loading magnitude is possible to modify by changing of excentric magnitude. Also if we change a length of connecting crank on the experimental equipment, there will be change in a loading cycle character (proportional-nonproportional loading, tension/tension loading, etc.). Power of device is secured by two synchronic electromotors with frequency converters from $0.5 \mathrm{~Hz}$ to $100 \mathrm{~Hz}$. Loading frequencies are identical with frequency of rotation drive. Synchronization of the electromotors is secured using electronics and allows synchronization of loading amplitudes. Synchronization of electromotors also allows setting phase shift for individual

\footnotetext{
* Corresponding author: lenka.jakubovicova@,fstroj.uniza.sk

Reviewers: Robert Grega, Radim Halama
} 
loading levels. In experimental equipment are also two force measure systems. These systems may be used to evaluate the force values during the loading process [3]. Our attention was focused on stress and strain conditions analysis by finite element method and on experimental measurement deformations by system ARAMIS in this paper.

\subsection{Material characteristics}

Two commercial aluminium alloys EN AW 6063.T66 (AlMgSi0,7.F25) and EN AW 2007.T3 (AlCuMgPb) were used for multiaxial fatigue testing. The chemical composition is shown in Tab. 1. Tested materials were bars with a circular section with diameter of $10 \mathrm{~mm}$. The EN AW 6063.T66 material was in pressing status, while EN AW 2007.T3 in drag status. The structure of both materials has been influenced by mechanical and heat treatment process. It was examined a tensile test and hardness measurement by Vickers, and metallographic analyses $[4,5]$.

Table 1. Chemical composition of aluminium alloys

\begin{tabular}{|c|c|c|c|c|c|c|c|c|c|c|}
\hline \multicolumn{11}{|c|}{ EN AW 6063} \\
\hline Si & $\mathbf{F e}$ & $\mathbf{C u}$ & Mn & Mg & $\mathrm{Cr}$ & $\mathbf{N i}$ & $\mathbf{Z n}$ & $\mathbf{T i}$ & Others components & Al \\
\hline $\begin{array}{l}0.2- \\
0.6 \%\end{array}$ & $0.35 \%$ & $0.1 \%$ & $0.1 \%$ & $\begin{array}{l}0.45- \\
0.9 \%\end{array}$ & $0.1 \%$ & - & $0.1 \%$ & $0.1 \%$ & $\begin{array}{l}\text { Max. } 0.05 \% \text { each } \\
\text { Max. } 0.15 \% \text { global }\end{array}$ & $\begin{array}{c}\text { Remaining } \\
\%\end{array}$ \\
\hline \multicolumn{11}{|c|}{ EN AW 2007} \\
\hline $\mathbf{S i}$ & $\mathbf{F e}$ & $\mathbf{C u}$ & Mn & Mg & $\mathrm{Cr}$ & $\mathbf{N i}$ & $\mathrm{Zn}$ & $\mathbf{T i}$ & Others components & Al \\
\hline $0.8 \%$ & $0.8 \%$ & $\begin{array}{l}3.3- \\
4.6 \%\end{array}$ & \begin{tabular}{|l|}
$0.5-$ \\
$1.0 \%$
\end{tabular} & \begin{tabular}{|l|}
$0.4-$ \\
$1.8 \%$
\end{tabular} & $0.1 \%$ & $0.2 \%$ & $0.8 \%$ & $0.2 \%$ & $\begin{array}{l}\text { Max. } 0.05 \% \text { each } \\
\text { Max. } 0.15 \% \text { global }\end{array}$ & $\underset{\%}{\text { Remaining }}$ \\
\hline
\end{tabular}

The material characteristics of fatigue specimen were obtained experimentally from tensile testing machine by STN EN 42 0310. The Stress-Strain diagram contains two curves - true stress and stress depending up strain (Fig. 1 and 2). For FEM analyses by ADINA were useful true stresses $[1,6]$.

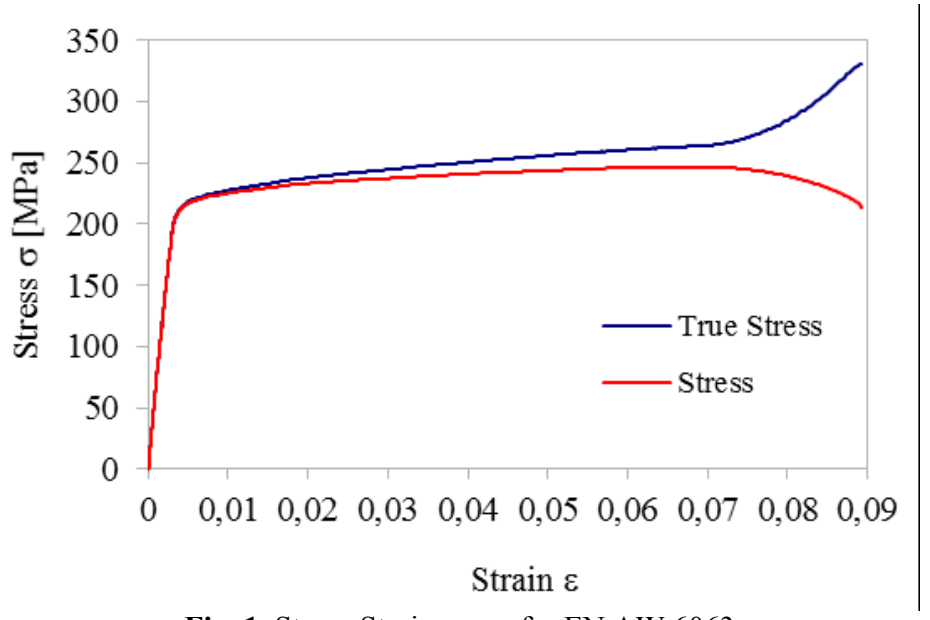

Fig. 1. Stress-Strain curve for EN AW 6063 


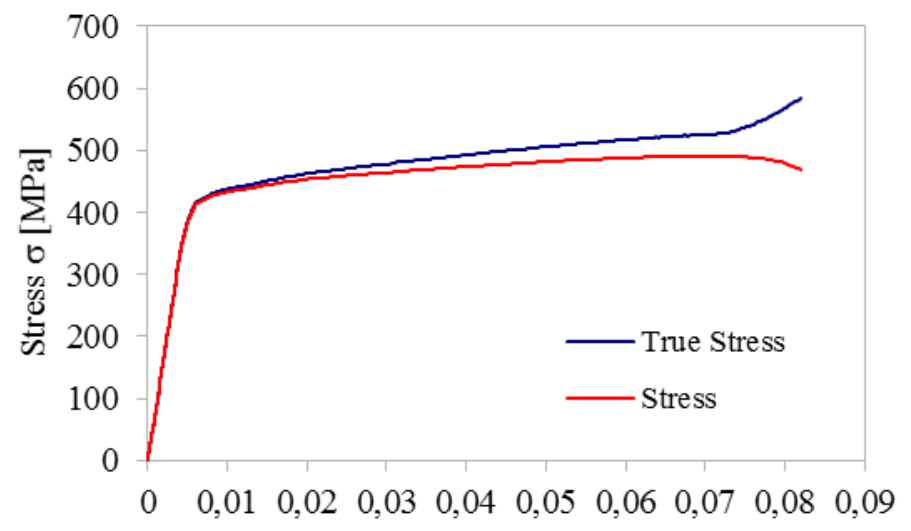

Strain $\varepsilon$

Fig. 2. Stress-Strain curves for EN AW 2007

\subsection{Loading degrees setting}

The loading regulation for bending and torsion were realized by excenter displacement according to body excenter. Power transfer from excenter to body excenter is assured by soft grooving what allows stepped setting whole eccentric system. This also allows exact setting of rocker arm.

Two pairs of excentric couple with fine grooving 40 under STN EN 014933 and setting maximum amplitude of 2 and $1 \mathrm{~mm}$ were prepared for both loading systems. In the case of maximal amplitude $2 \mathrm{~mm}$ the excenter body and excenter were made with eccentricity of $1 \mathrm{~mm}$. In case of maximal amplitude $1 \mathrm{~mm}$ the eccentricity was $0.5 \mathrm{~mm}$. Excenter has 37 teeth, so it is possible to set 37 loading levels. Setting scheme of eccentricity is presented on Fig. 3.

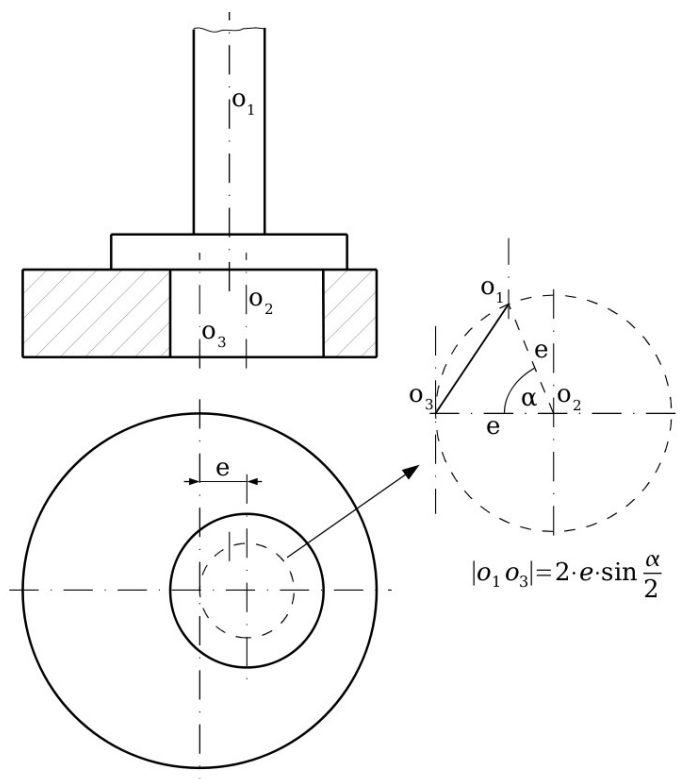

Fig. 3. The eccentricity setting 


\section{Stress-strain results obtained by optical system ARAMIS}

ARAMIS is contactless optical system based on three-dimensional measurement to evaluate displacement at static or dynamic loading. With the software ARAMIS can be analysed, calculated and documented a deformation process where the results from these photos provide optimal interpretation of object behaviours.

ARAMIS system consists from optical camera, which caches the surface object. By the software can be recognized the structure of surface from taken digital photos and assign coordinates to showed pixels (Fig. 4). Then ARAMIS compare digital photos and calculates displacements of individual pixels and evaluate deformation. It is very important to have specimens with sprayed layer for this process. For this reason it is usual combination black and white spray colour applied on surface of specimens (Fig. 5).

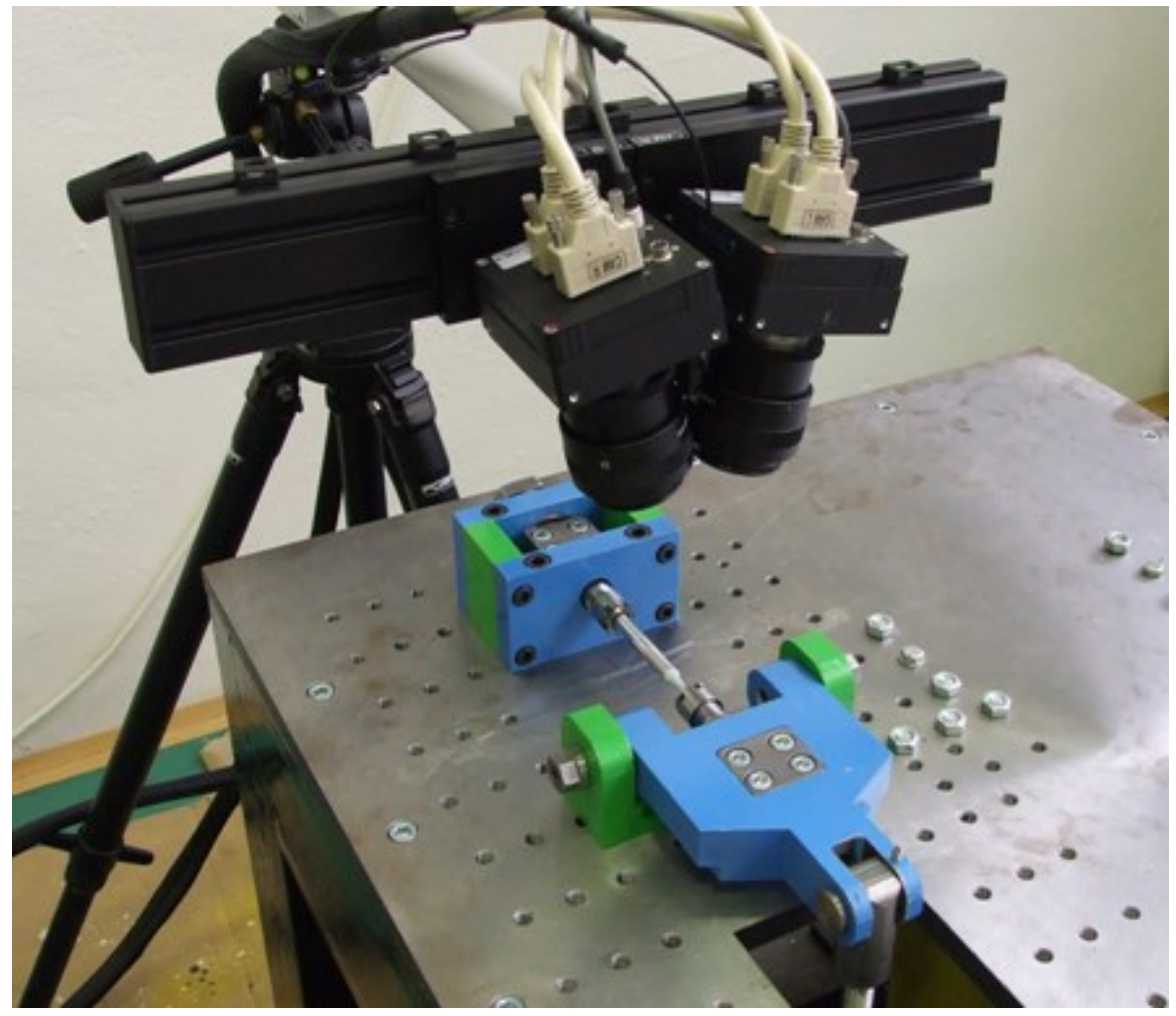

Fig. 4. The camera system ARAMIS caching the surface of loading object

The measure of cyclic deformation were made under loading frequency $0.5 \mathrm{~Hz}$, while camera system takes the digital photos with frequency $30 \mathrm{~Hz}$ (30 pictures per second) [2]. The maximum values of displacements were measured at the specimen radius, where were applied sampling mask (Fig. 5). The displacement area is displayed on each photo (Fig. 6) and time history was created at the point of maximal displacements (Fig. 7). Dominant values for cyclic loading are $\varepsilon_{x x}$ and dominant values for cyclic torque loading are $\gamma_{x y}$. 


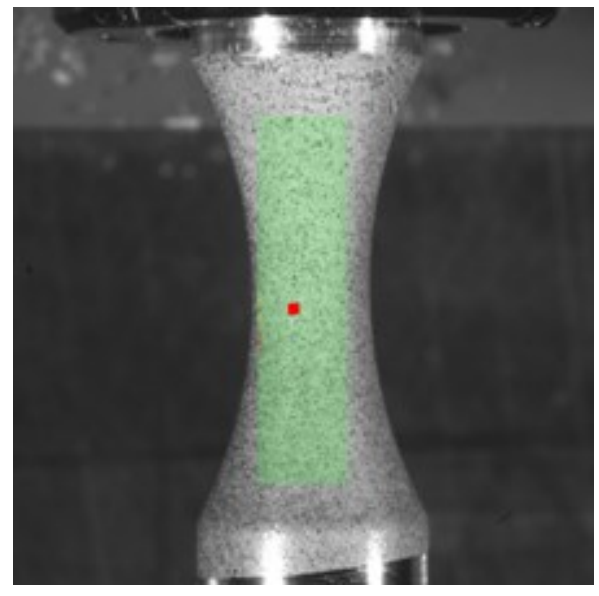

Fig. 5. The photo analysed by system ARAMIS with "sampling mask"

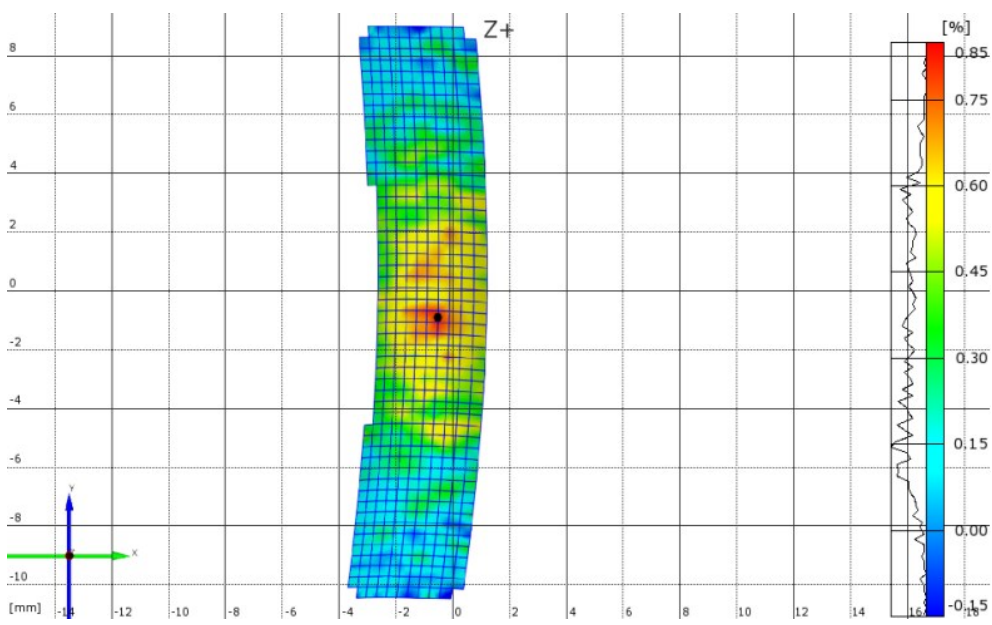

Fig. 6. Displacements at sampling mask

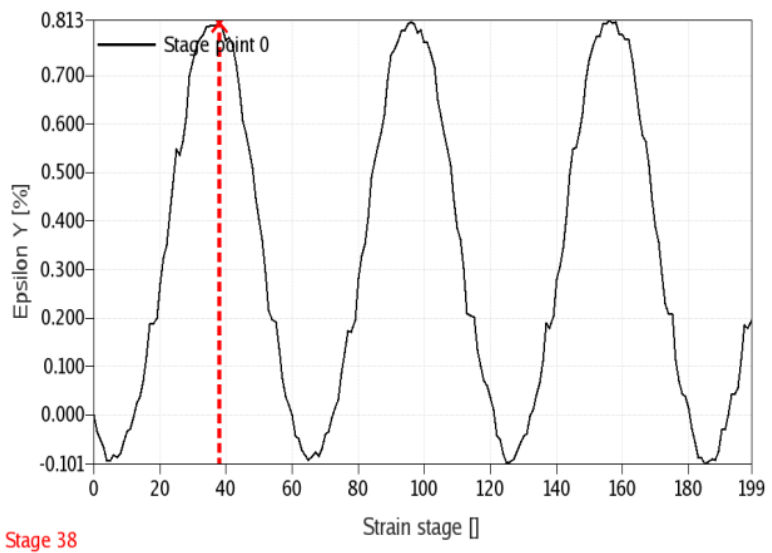

Fig. 7. The time history of displacements by each photo 


\section{Stress-strain FE analysis of test specimen}

It is necessary to know plastic strain amplitude (Manson-Coffin curve) or stress amplitude (Wöhler curve) on each loading level for fatigue test interpretation [7]. Therefore, it is necessary to analyse stress and strain at the maximum values by FEM. The specimen model was created by FE software ADINA (Fig. 8) [6,8].

The material was assumed as plastic-bilinear; the true stresses were obtained from real stress-strain curves on Figs. 1 and 2. The linear element of tetrahedron type was automatically generated. The "Load Plot" function was defined by excenter setting with 37 steps with eccentricity of $1 \mathrm{~mm}$ or $2 \mathrm{~mm}$. The shell and beam elements for hammer simulation were used at the fix point.

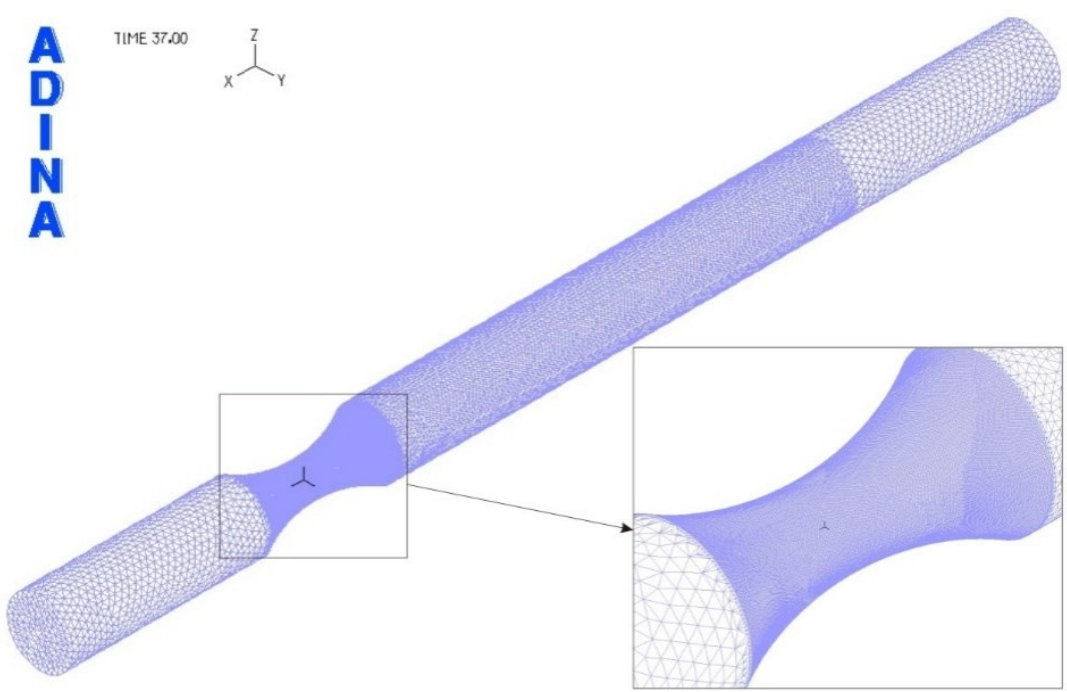

Fig. 8. FE model of specimen

The maximum stress and strain values are concentrated in specimen radius. It has been shown from computational analysis of stress conditions. There was obtained stress-strain values at the specimen radius (Fig. 9 to Fig. 12).

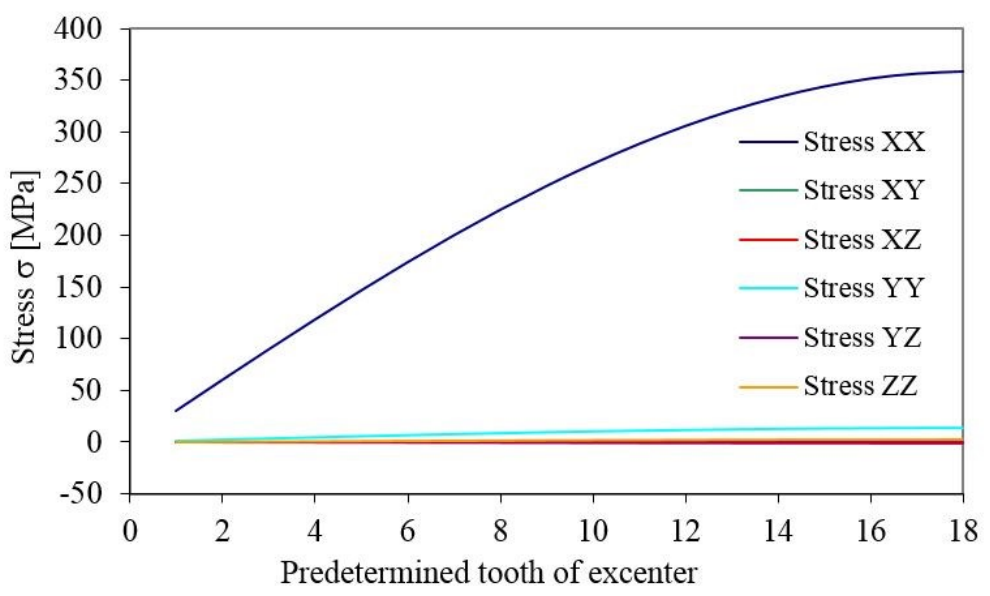

Fig. 9. Bending: Stress values for EN AW 2007 and eccentricity $1 \mathrm{~mm}$ 
The results associate to eccentricity $e=1 \mathrm{~mm}$. For bending we can determinate that the stress and strain values have a dominant values; it means stress $\sigma_{x x}$ and strain $\varepsilon_{x x}$. The same phenomenon has been observed for the torsion at the stress and strain values; it means stress $\sigma_{x y}$ and strain $\varepsilon_{x y}[9,10]$. Obtained stress values allow determine the plastic deformation amplitude for each load step (turning step by step the gear - 37 steps $=1$ turn). It was determined a deformation $\varepsilon_{x x}$ during the bending sinusoidal cycle of loading and screw angle $\gamma_{x y}$ was determined during the torsion sinusoidal cycle of loading.

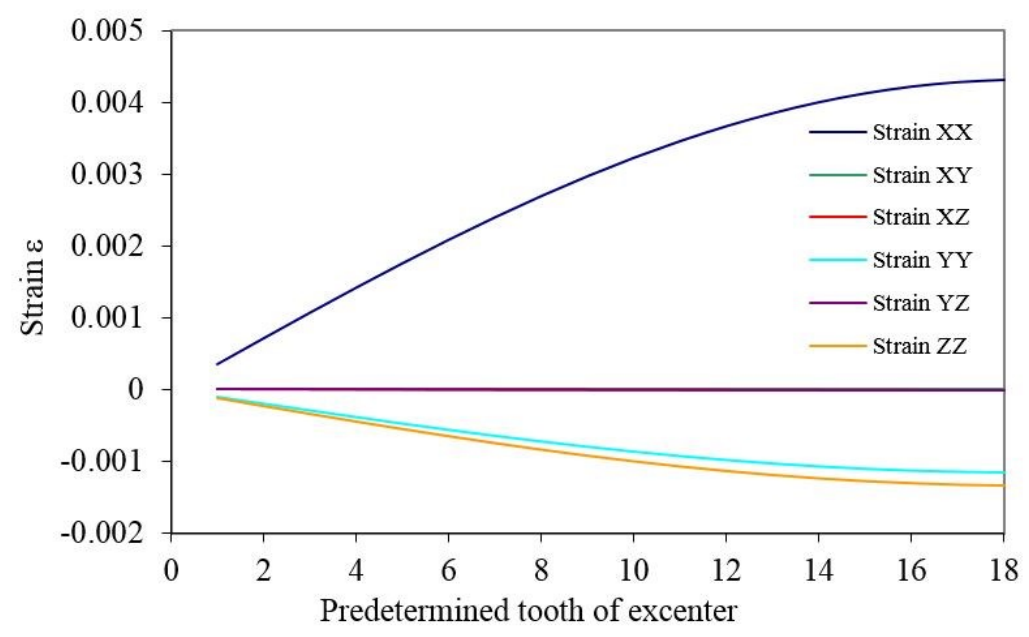

Fig. 10. Bending: Strain values for EN AW 2007 and eccentricity $1 \mathrm{~mm}$

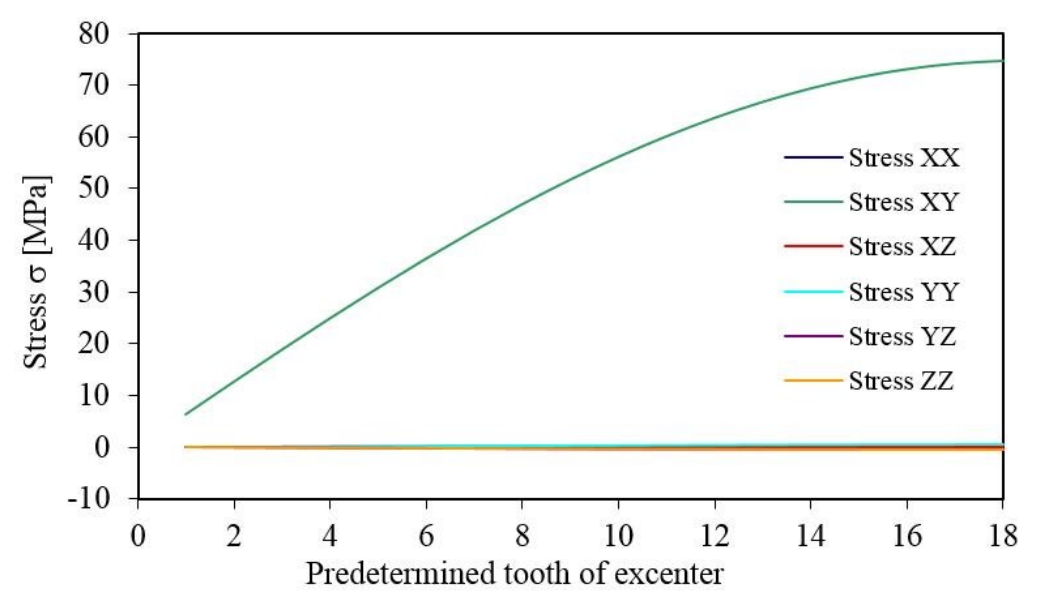

Fig. 11. Torsion: Stress values for EN AW 2007 and eccentricity $1 \mathrm{~mm}$ 


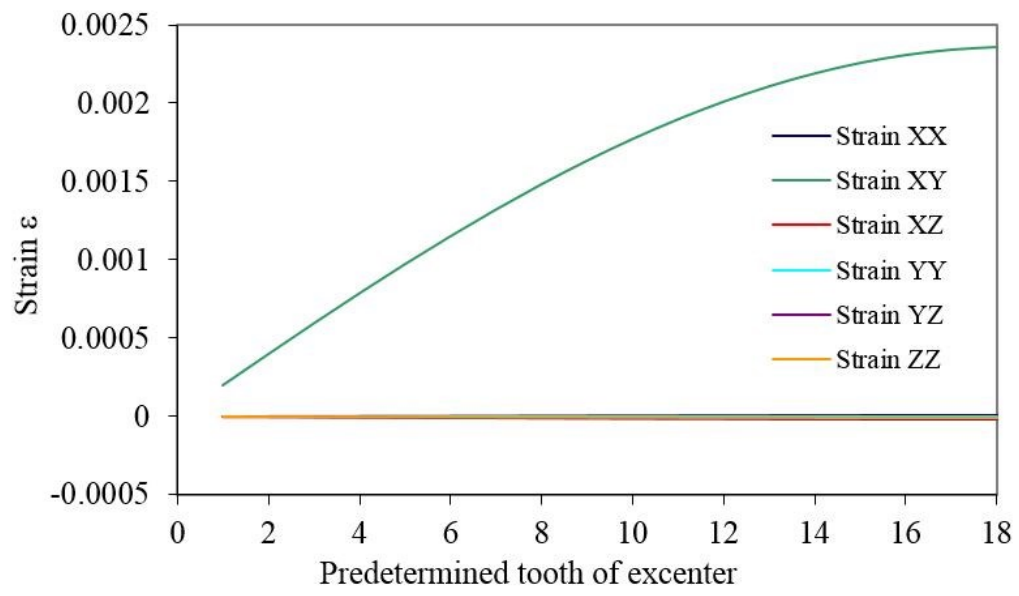

Fig. 12. Torsion: Strain values for EN AW 2007 and eccentricity $1 \mathrm{~mm}$

\section{Comparison of Stress-strain FE and ARAMIS analyses}

The measurement by optical system ARAMIS was realized at the load level equal to eccentricity setting to uneven number of teeth. The obtained strain results from ARAMIS compared with obtained results by FE method are shown in Fig. 13 to Fig. 16. The results obtained by optical system ARAMIS at the sinusoidal cycle bending was low increasing like results obtained from FEM analyses.

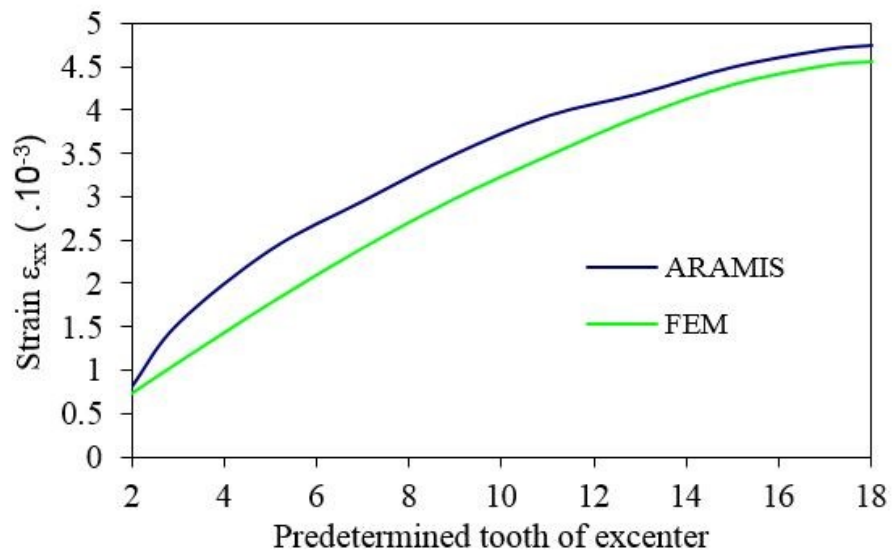

Fig. 13. The strain $\varepsilon_{x x}$ obtained by optical system ARAMIS vs. FEM (bending, EN AW 6063, eccentricity $1 \mathrm{~mm}$ ) 


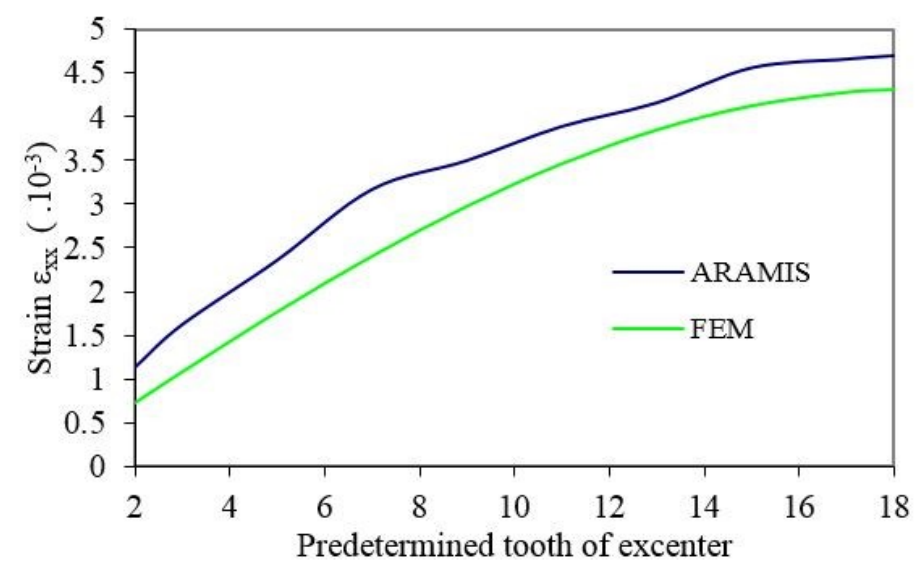

Fig. 14. The strain $\varepsilon_{x x}$ obtained by optical system ARAMIS vs. FEM (bending, EN AW 2007, eccentricity $1 \mathrm{~mm}$ )

During evaluation of points displacement by ARAMIS system interpreted the measure of shearing strain value $\varepsilon_{x y}$, ADINA software interpreting shearing strain values $\gamma_{x y}$ on the base of FE analyses $[1,11]$. It can be seen that the value obtained by ARAMIS system must be for the FE analyses multiplied by two from this reason, i.e.

$$
\varepsilon_{x y}=\frac{1}{2} \gamma_{x y} .
$$

The obtained results from ARAMIS and from FE analysis in the case of the sinusoidal torsion are shown in Fig. 14 and Fig. 15. The strain values obtained from FEM and strain values obtained from ARAMIS system indicated relatively good agreement at all load steps for bending-torsion cycle sinusoidal loading $[2,12,13]$.

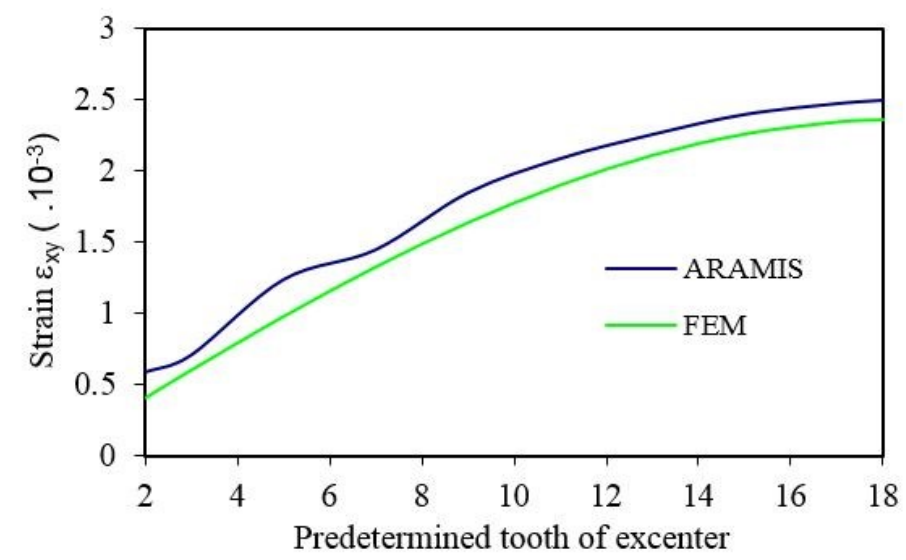

Fig. 15. The strain $\varepsilon_{x y}$ obtained by optical system ARAMIS vs. FEM (torsion, EN AW 6063, eccentricity $1 \mathrm{~mm}$ ) 


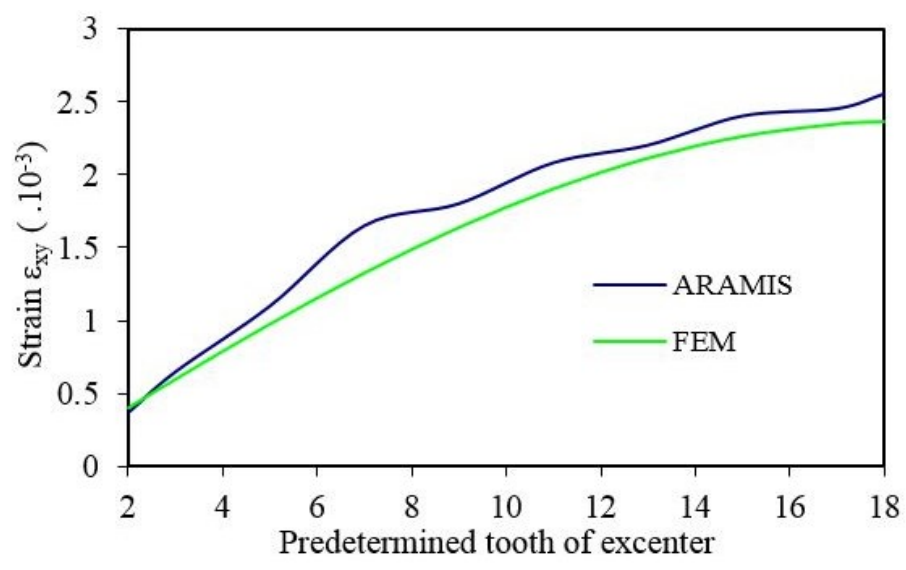

Fig. 16. The strain $\varepsilon_{x y}$ obtained by optical system ARAMIS vs. FEM (torsion, EN AW 2007, eccentricity $1 \mathrm{~mm}$ )

\section{Calibration curves for EN AW 6063 and EN AW 2007 materials}

The measured values of deformation $\varepsilon$ by system ARAMIS and also the commutated values of deformation $\varepsilon$ by FEM have good correlation for aluminium alloy. In the future it will be interesting in combination of bending and torsion loading therefore it is necessary to have calibration curve for each level of loading (Fig. 17 and 18).

So if we want to set a deformation on exact value for torsion loading, we must backwards to establish a number of tooth for setting of excenter from calibration curve, see Eq. (1) to Eq. (4). Than we can provide the cycle sinusoidal loading for determine multiaxial fatigue life-time characteristic.

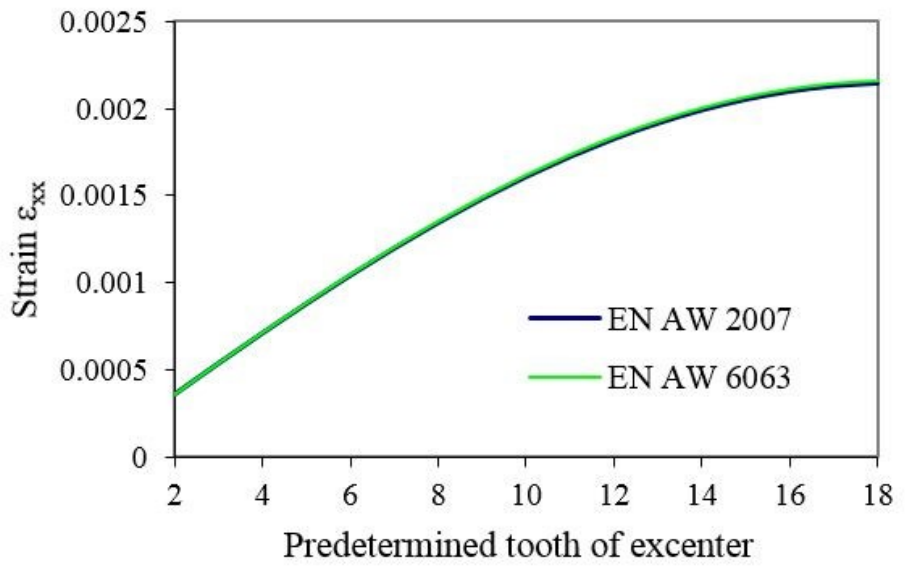

Fig. 17. Bending: The calibration curve for eccentricity $0.5 \mathrm{~mm}$

Strain calibration curve $\left(\varepsilon_{x x}\right)$ for EN AW 2007 and EN AW 6063 material and for eccentricity:

- $0.5 \mathrm{~mm}: \quad n_{\text {tooth }}=\left(-0.0002 \varepsilon_{x x}{ }^{3}-0.001 \varepsilon_{x x}{ }^{2}+0.187 \varepsilon_{x x}-0.0071\right) \cdot 10^{-3}$,

- $1 \mathrm{~mm}: \quad n_{\text {tooth }}=\left(-0.0003 \varepsilon_{x x}{ }^{3}-0.0017 \varepsilon_{x x}{ }^{2}+0.372 \varepsilon_{x x}-0.014\right) \cdot 10^{-3}$. 


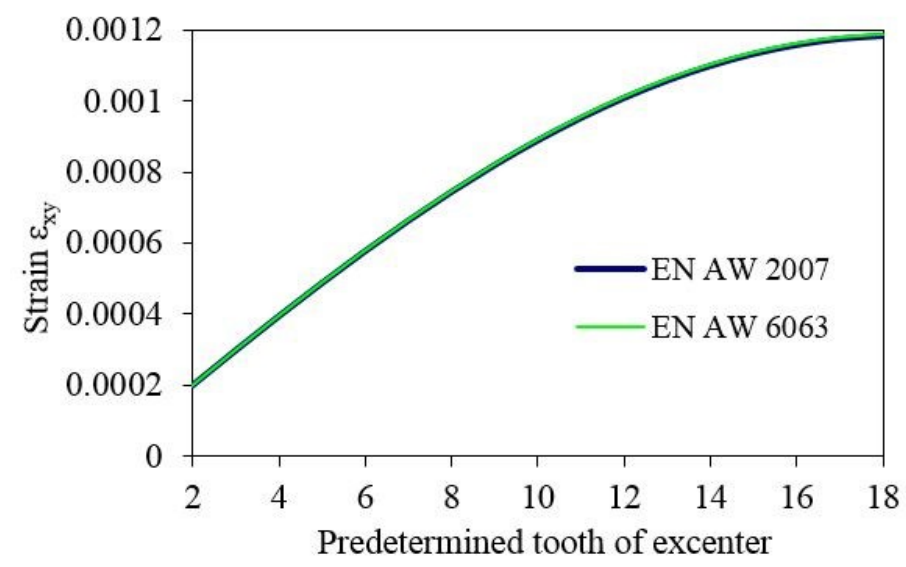

Fig. 18. Torsion: The calibration curve for eccentricity $0.5 \mathrm{~mm}$

Strain calibration curve $\left(\varepsilon_{x y}\right)$ for EN AW 2007 and EN AW 6063 material and for eccentricity:

$-0.5 \mathrm{~mm}: \quad n_{\text {tooth }}=\left(-0.0001 \varepsilon_{x y}{ }^{3}-0.0007 \varepsilon_{x y}{ }^{2}+0.1039 \varepsilon_{x y}-0.004\right) \cdot 10^{-3}$,

- $1 \mathrm{~mm}: \quad n_{\text {tooth }}=\left(-0.0002{\varepsilon_{x y}}^{3}-0.0013{\varepsilon_{x y}}^{2}+0.2069 \varepsilon_{x y}-0.008\right) \cdot 10^{-3}$.

\section{Conclusion}

Our paper deals with determination of the calibration curve for combined loading (bending and torsion) using numerical and experimental evaluating. Analyses were realized for EN AW 6063 (AlMgSi0,7.F25) and EN AW 2007 (AlCuMgPb) materials.

The numerical calculations were realized by Finite Element Method and results were verified with the experimental measurement applying the optical system ARAMIS. The results have shown an independence of the strain calibration curve on the material type.

This work was supported by the Slovak Research and Development Agency under the contract No. APVV-14-0096 and by grant KEGA 015ŽU-4/2017 - Digital technologies for machine building study programs as a part of strategy "Internet of Things".

\section{References}

1. K. J. Bathe, Finite Element Procedures. (Prentice Hall, New Jersey, 1982)

2. A. Sapietová, V. Dekýš, Dynamic analysis of rotating machines in MSC.ADAMS. Procedia Engineering 136, 143-149 (2016)

3. M. Handrik, P. Kopas, V. Baniari, M. Vaško, M. Sága, Analysis of stress and strain of fatigue specimens localised in the cross-sectional area of the gauge section testing on bi-axial fatigue machine loaded in the high-cycle fatigue region. Procedia Engineering 177, 516-519 (2017)

4. W. Piekarska, M. Kubiak, Z. Saternus, Numerical simulation of deformations in T-joint welded by the laser beam. Archives of Metallurgy and Materials 58 (4) 1391-1396 (2013) 
5. A. Vaško, J. Belan, L. Kuchariková, E. Tillová, Low and high frequency fatigue tests of nodular cast irons. Metalurgija 56 (1-2), 25-28 (2017)

6. ADINA, Theory and Modelling Guide. [help manual] (Watertown, 2010)

7. P. Kopas, M. Blatnický, M. Sága, M. Vaško, Identification of mechanical properties of weld joints of AlMgSi07.F25 aluminium alloy. Metalurgija 56 (1-2), 99-102 (2017)

8. J. Kortiš, L. Daniel, M. Handrik, The Numerical Analysis of the Joint of the Steel Beam to the Timber Girder. Procedia Engineering 91, 160-164 (2014)

9. L. Jakubovičová, B. Ftorek, V. Baniari, A. Sapietová, T. Potoček, M. Vaško, Engineering Design of Test Device. Procedia Engineering 177, 520-525 (2017)

10. J. Gerlici, T. Lack, Contact geometry influence on the rail/wheel surface stress distribution. Procedia Engineering 2 (1), 2249-2257 (2010)

11. R. Grega, J. Homišin, J. Krajňák, M. Urbanský, Analysis of the impact of flexible couplings on gearbox vibrations. Scientific Journal of Silesian University of Technology-Series Transport 91, 43-50 (2016)

12. R. Halama, A. Markopoulos, F. Fojtík, M. Fusek, Z. Poruba, J. Famfulík, Effect of stress amplitude on uniaxial ratcheting of aluminum alloy 2124-T851. Materialwissenschaft und Werkstofftechnik 48 (8), 814-819 (2017)

13. R. Grega, J. Krajňák, L. Žul'ová, G. Fedorko, V. Molnár, Failure analysis of driveshaft of truck body caused by vibrations. Engineering Failure Analysis 79, 208-215 (2017) 